\title{
AMOS-based analysis of factors influencing customer loyalty
}

\author{
Qinying Zhu, Luyang Yu, Jing Luo, Songlin Cao* \\ Hunan University of Finance and Economics, Changsha 410205, China
}

\begin{abstract}
In order to better reduce the cost of e-commerce operations and save resources for marketing promotion, e-commerce merchants must adopt a reasonable and effective way to screen customers and improve the competitiveness of their own products. This paper takes the measurement of latent variable customer loyalty as the starting point, collects data through the design of questionnaires as the research basis, and uses Analysis of Moment Structure (AMOS) to construct structural equation model to conduct a validating factor analysis. It was found that the hypotheses proposed from the three subjects of business, customers themselves and logistics are all basically valid, and all three have a positive impact on loyalty. Ecommerce businesses should improve the service quality of their stores, ensure that their products can meet the needs of most customers, and build a good brand image, and should also carefully choose logistics companies that are reliable and new to customers to cooperate with.
\end{abstract}

\section{Introduction}

According to the Statistical Report on the Development Status of the Internet in China ${ }^{[1]}$, the number of Internet users using online payment reached 569 million in June 2018, showing a rising trend year by year. Alibaba Group announced its first-quarter financial results for fiscal year 2019, showing that Ali's core e-commerce business revenue reached 69.188 billion yuan. For this reason, merchants need to discover new customers as well as increase the likelihood of repeat purchases from existing customers in order to maximize profits.

Online shopping customer loyalty is generally accepted as "a customer's subjective decision to repurchase a merchant's goods and services out of recognition and acceptance of the merchant's goods and services" ${ }^{[2]}$. This paper aims to study customer loyalty by analyzing the service quality of different businesses, corporate branding and marketing, customer satisfaction and trust, and the speed and service of third-party logistics.

\section{Related Works}

Since the 1960s, paperless trade EDI e-commerce began to develop. The earliest rise of e-commerce in the United States, the American Customer Satisfaction Index Model (ACSI) [3] to the customer as the main body, from customer perception, perceived quality, perceived value to derive the degree of customer satisfaction, and then by the satisfaction to determine the outcome of customer complaints or customer loyalty. European Customer Satisfaction Index Model (ECSI) [3] and ACSI model to the customer as the main body, but also mentioned customer expectations, perceived quality and perceived value, customer satisfaction to determine the degree of loyalty, adding the direct impact of corporate image on customer loyalty, and eliminated by customer dissatisfaction brought about by the results of customer complaints. .

Domestic e-commerce sprouted in 1997-1999, with the rapid development of the domestic Internet, domestic e-commerce has also risen into a period of rapid development, most of the domestic research on loyalty also appeared at this time.

\section{Models and theories}

\subsection{Amos}

Analysis of Moment Structure(Amos)was developed by James L. Arbuckle and is suitable for covariance structure analysis to deal with complex multivariate data. Relevant hypotheses are proposed, and the Amos structural equation model is used for modeling and analysis and data processing in order to obtain the factors and paths that influence customer loyalty.

\section{2 structural equation model (SEM)}

Structural equation model is a statistical method to analyze the relationship between variables based on their covariance matrices and is an important tool for multivariate data analysis. The commonly used analysis software for structural equation modeling are LISREL, Amos, EQS, MPlus. structural equation modeling can be divided into measurement modeling and structural

caosonglin@hufe.edu.cn* 
modeling. The measurement model refers to the relationship between indicators and latent variables. The structural model refers to the relationship between the latent variables.

\section{Empirical analysis and experiments on customer loyalty}

\subsection{Data acquisition and profiling}

In this study, the design of the questionnaire was based on the three subjects of enterprises, customers and logistics services to set up primary indicators, and then subdivided into secondary indicators, and finally 503 valid questionnaires were collected.
It can be seen from the graph that the majority of the total are women (57.7 per cent), compared to men (42.3 per cent); users are concentrated in the two age groups of 18-30 and 30-55 years. Students are in the first place with $68 \%$ of the overall sample, while working people make up $24.5 \%$ of the overall sample. Bachelor's degrees make up 40.2 percent of the sample, followed by master's degrees at 19.6 percent, less than a high school degree and doctorates, and a majority of bachelor's degrees. Those with incomes between 2000 and below and 2001-4999 accounted for 70\% of the sample. The results of the questionnaire were influenced by the student status of the questionnaire publishers, which caused the distribution of occupation and economic income to be slightly different from that of Tmall, but the overall data of the sample were basically consistent.

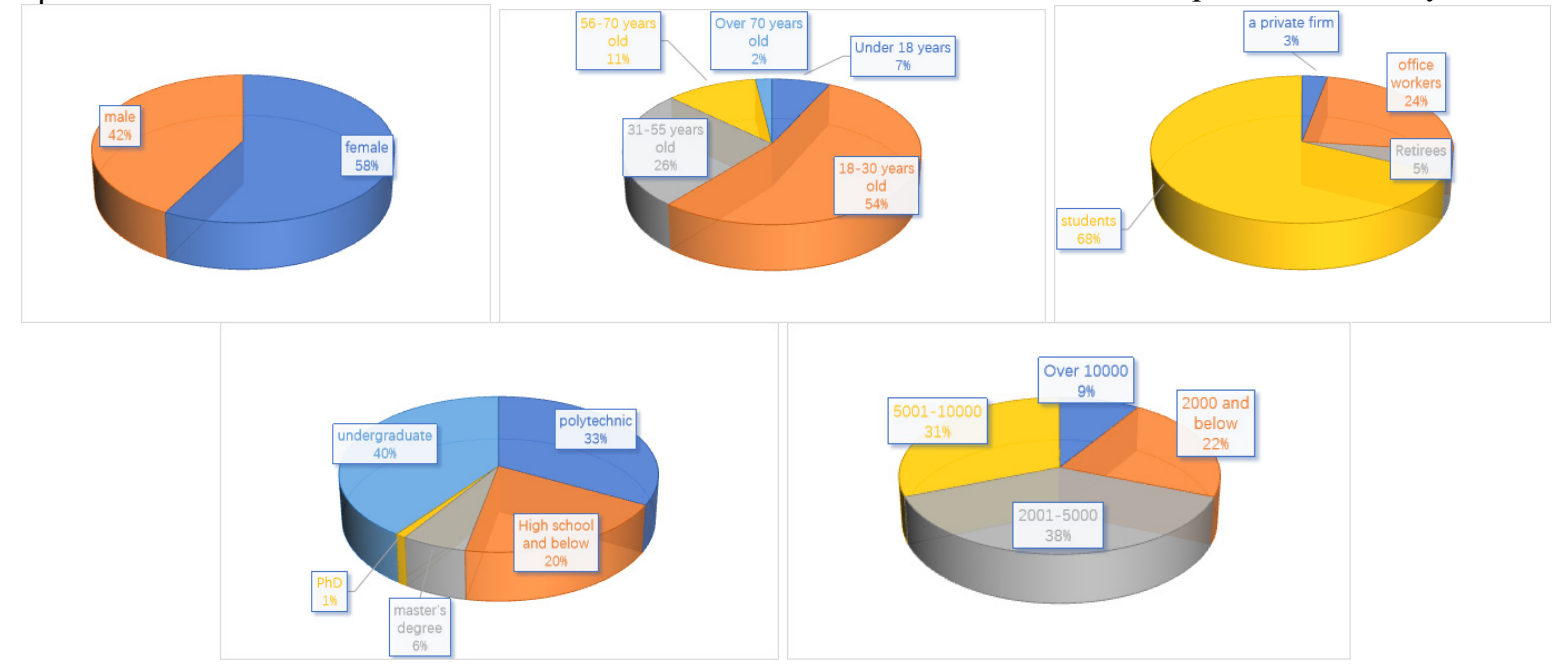

Figue 1 Pie chart of distribution by sex, age, occupation, education level and economic income

\subsection{Confidence analysis and factor analysis}

As shown in Figure 2, the reliability analysis of the data resulted in a good confidence level of 0.880 and no adjustment for the problematic items was required.

As shown in Figure 3, Bartlett's test $p<0.05$, indicating that the variables are significantly correlated and suitable for factor analysis.The further factor loadings are almost the same as the original settings, so there are the following divisions: service quality, corporate brand and corporate marketing with a total of 9 items extracted as corporate factors; customer satisfaction and customer trust with a total of 6 items extracted as customer factors; logistics speed and logistics services with a total of 5 items extracted as logistics factors.

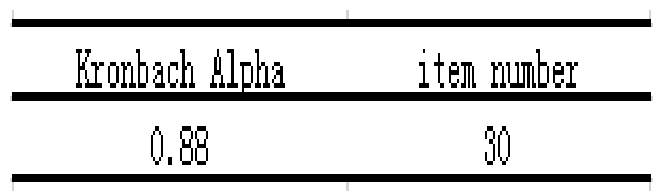

Figue 2 Reliability statistics results

\begin{tabular}{lcc}
\hline KMO sampletangibility & Approximation of the & 0.949 \\
\hline Bartlett spherical test & degree of freedom & 3538.376 \\
& saliency & 300 \\
& & 0.000 \\
\hline
\end{tabular}

Figure $3 \mathrm{KMO}$ and Bartlett test

\subsection{Construction of structural equation models}

For better representation and explanation, the firm factor, customer factor and logistics factor are replaced by A, B and $\mathrm{C}$, respectively, and the question items under these three factors are replaced by the ordinal numbers $1,2,3$, etc. Before the testing and construction of the structural equation model, the fit indices in Fig 4 were used as a reference benchmark. 


\begin{tabular}{|l|l|l|l|l|l|l|l|l|l|}
\hline test index & $\begin{array}{l}\text { X2/d. } \\
\mathrm{f}\end{array}$ & GFI & AGFI & NFI & CFI & IFI & RMR & $\begin{array}{l}\text { RMSE } \\
\text { A }\end{array}$ & P \\
\hline recommended value & $>3$ & $>0.90$ & $>0.80$ & $>0.90$ & $>0.90$ & $>0.90$ & $<0.08$ & $<0.08$ & $\begin{array}{l}<0.0 \\
5\end{array}$ \\
\hline
\end{tabular}

Figue 4 Proposed table of fit indices

\subsubsection{Differential validity test of the independent variable}

In this study, we need to compare the enterprise factor, customer factor and logistics factor, and construct the unrestricted model (without setting parameters) and the restricted model (assuming the parameter is 1, that is, the correlation between them is 1 , completely correlated) between the two factors, and observe the results. 0 , less than 0.05 ; the difference between their cube values is about 91; the cube test for the unrestricted model of customer factor and logistics factor is 0 , less than 0.05 ; the cube test for the restricted model is also 0 , less than 0.05 ; the difference between their cube values is about 120; the cube test for the unrestricted model of logistics factor and firm factor is 0 , less than 0.05 ; the cube test for the restricted model is also 0 , less than It means that the difference validity between customer factor, logistics factor and enterprise factor is good.

\subsubsection{Aggregate validity test for independent variables}

In this study, it is necessary to test the aggregation validity of each variable (i.e., problem item) under the firm factor, customer factor, and logistics factor. In general, the higher the fit superiority index, the better the aggregation effectiveness. According to the suggested fit index table above, the fit superiority index reaches a critical value of 0.9 before the test is passed. The results of the aggregation validity test of the eight variables of the firm factor using the AMOS software previously assumed that there was no correlation between the individual error terms, but since the fit superiority index CFI was below 0.9 , the relationship between the eight variables under the firm factor needed to be adjusted. After adjusting the relationship between the variables, the aggregation validity of the eight variables under the enterprise factor is good, with a CFI of 0.99 and the other correlation indices also meet the requirements of the proposed fit index table, indicating that the adjusted model and data import are in good agreement, and the modeling can be carried out in the next step.

\subsubsection{Adjustments to the structural equation model}

Based on the results of the differentiated validity test for the three factors of business factors, customer factors, and logistics factors, as well as the results of the aggregated validity test for the secondary indices of these three factors respectively, the AMOS software was used to construct a structured equation model.

Based on the initial standardized fit indices, the model continued to be modified by comparing it with the suggested table of fit indices in the previous section and found that some indices did not reach the suggested values, especially the fit superiority index CFI of 0.831 did not reach the critical value of 0.9 .

\subsubsection{Final Structure Model Equation Model}

\begin{tabular}{|c|c|c|c|c|}
\hline & & \begin{tabular}{|l} 
Custocenr \\
factors
\end{tabular} & $\begin{array}{l}\text { Corporate } \\
\text { actors }\end{array}$ & $\begin{array}{l}\text { Lofistics } \\
\text { factors }\end{array}$ \\
\hline \multirow{3}{*}{ Carporate Pactors } & direct effoct & 0.795 & & \\
\hline & indirect effect & & & \\
\hline & ateregate offoct & 0.795 & & \\
\hline \multirow{3}{*}{ Loeistics factors } & direct effoct & & 0.697 & \\
\hline & indirect effect & 0.544 & & \\
\hline & aerregate offoct & 0.544 & 0.697 & \\
\hline \multirow{3}{*}{ Custoner factors } & diroct offoct & 0.268 & 0.218 & 0.393 \\
\hline & indiroct effect & 0.394 & 0.277 & \\
\hline & aerregate offoct & 0.662 & 0.495 & 0.393 \\
\hline
\end{tabular}

Figue 5 Table of results for inter-variable effects

Based on the above modifications and adjustments to the model, the final structural equation model for customer loyalty was obtained as follows. 


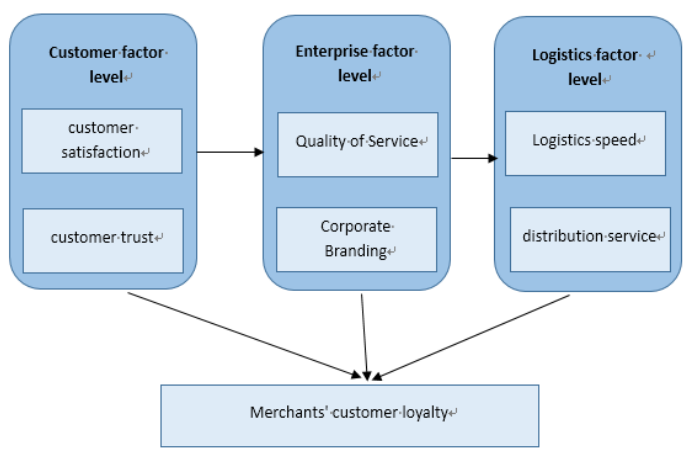

Figue 6 Final model diagram

\subsubsection{Research hypothesis validation}

(1) The Pearson correlation coefficients of enterprise factors (product and service quality, corporate brand image), customer factors (customer satisfaction, customer trust), logistics factors (logistics and distribution speed, incoming and outgoing distribution services) and customer loyalty and loyalty are all significantly correlated above 0.6 , indicating that all three have a positive effect on loyalty, which is consistent with the previous hypothesis.

(2) Among the three factors affecting customer loyalty, the total effect is ranked from high to low as customer factors, enterprise factors, and logistics factors; the direct effect is ranked from high to low as logistics factors, customer factors, and enterprise factors. To improve customer loyalty, one of the three perspectives is indispensable.

(3) The influence of the three factors of enterprise, customer and logistics on customer loyalty is not independent of each other, but has a certain correlation: the enterprise factor will have a certain influence on the customer itself, and ultimately affect the customer's loyalty; and the third-party logistics to join the cooperation with the enterprise, the enterprise factor also has a certain effect. The three interact with each other, and ultimately play a role in user loyalty.

\section{Conclusion}

This study uses Tmall, an e-commerce platform with a wide distribution of users, as the object of use, and the final conclusion is that the hypothesis proposed from the three subjects, namely, the enterprise, the customer itself and logistics, is basically valid, and all three have a positive impact on loyalty. For each of the influencing factors, businesses can build the following aspects to improve customer trust and customer loyalty: improve and control product quality, build a responsible corporate image, carefully choose logistics companies to cooperate with, and improve customer satisfaction and trust.

\section{Acknowledgments}

This work was supported in part by the National Natural Science Foundation of China, grant number 72073041. Open Foundation for the University Innovation Platform in the Hunan Province, grant number 18K103; $2011 \mathrm{Col}$ laborative Innovation Center for Development and Utiliz ation of Finance and Economics Big Data Property, Univ ersities of Hunan Province. Open project, grant number 2 0181901CRP03, 20181901CRP04, 20181901CRP05. 20 20 Hunan Provincial Higher Education Teaching Refor ResearchProject under Grant HNJG-20201124, HNJG-2020-

1130. 2020 General Project of Hunan Social Science Fu nd under Grant 20B16.

\section{References}

1. CNNIC releases the 43rd Statistical Report on the Development Status of the Internet in China[J]. NetInfo Military and Civil Integration,2019(02):3738.

2. Zhai Qinghua, Ye Minghai. An empirical study of the factors influencing customer loyalty in online shopping[J]. Economic Forum, 2009(18):128-131.

3. Chen Jingyuan. An analysis of the factors influencing customer loyalty based on Tmall platform[D]. Northwest Agriculture and Forestry University of Science and Technology,2018. 